\title{
Correction to: Social and environmental determinants of child health in Mongolia across years of rapid economic growth: 2000-2010
}

Nehal Joshi ${ }^{1}$, Bolormaa Bolorhon ${ }^{2}$, Indermohan Narula ${ }^{3}$, Shihua Zhu ${ }^{4}$ and Semira Manaseki-Holland ${ }^{5^{*}}$

\section{Correction}

Unfortunately, after publication of this article [1], it was noticed that an error during the production process resulted in an incorrect author name. The author Semira Manaseki-Holland is incorrectly displayed as Semira Manaseki-Hollan. The full, corrected author list can be seen above.

\begin{abstract}
Author details
'Medicine, University of Birmingham, Birmingham, UK. '² Medical Student, Health Sciences University of Mongolia, Ulaanbaatar, Mongolia. ${ }^{3}$ Team Leader, Global Fund LFA, Ulaanbaatar, Mongolia. "Research Fellow in Health Economics and Mathematical Modelling, Public Health, Epidemiology and Biostatistics, School of Health and Population Sciences, College of Medical and Dental Sciences, University of Birmingham, Birmingham, UK. ${ }^{5}$ Clinical Senior Lecturer, Department of Public Health, Epidemiology and Biostatistics, School of Health and Population Sciences, College of Medical and Dental Sciences, University of Birmingham, Birmingham, UK.
\end{abstract}

Received: 12 March 2018 Accepted: 12 March 2018

Published online: 22 March 2018

\section{Reference}

1. Joshi N, Bolorhon B, Narula I, Zhu S, Manaseki-Hollan S. Social and environmental determinants of child health in Mongolia across years of rapid economic growth: 2000-2010. Int J Equity Health. 2017;16:189. https:// doi.org/10.1186/s12939-017-0684-x

\footnotetext{
* Correspondence: S.ManasekiHolland@bham.ac.uk

${ }^{5}$ Clinical Senior Lecturer, Department of Public Health, Epidemiology and Biostatistics, School of Health and Population Sciences, College of Medical and Dental Sciences, University of Birmingham, Birmingham, UK
} 